\title{
The Clinical Importance of the Os Peroneum: A Dissection of 156 Limbs Comparing the Incidence Rates in Cadavers versus Chronological Roentgenograms
}

\author{
by Brion Benninger, $\mathrm{MD}^{1} \square$, Jessica Kloenne ${ }^{2}$
}

The Foot and Ankle Online Journal 4 (2): 2

Introduction: The purpose of this study was to assess radiograph incidence versus cadaver incidence rates of the os perineum (OP) within the fibularis (peroneus) longus tendon (FLT) and to assess why broad variants have occurred in previous radiograph and cadaver studies. The OP or sesamoid bone in the FLT has a history of controversy regarding the terminology and frequency. Recent histological studies have proven sesamoid terminology. Cadaver studies have revealed high incidence rates (IR), yet virtually all texts and atlases exclude it. Clinicians recognize it in routine foot radiographs. No studies have compared IRs between cadavers and injured patients of the general population.

Methods: A literature search of texts, atlases, journals and websites was conducted identifying incidence of OP within the FLT. Dissection of 82 embalmed cadavers (M 52, F 30) identified the IR of the OP. Oblique foot radiographs from 1,025 individuals were examined.

Results: A literature review revealed OP in 20\% of atlases, $7.69 \%$ in texts, and previous cadaver study results are $46 \%, 90 \%$, and 14.9\%. This study's cadaver results reported an IR of $88.46 \%$ with an average age of 78.1 (45$89 y r s)$. Radiographic results revealed $15.12 \%$ incidence with an average age 41.97 (10 - 89yrs). The average IR from 10 to 70 years was $13.32 \%$. From 70 onwards it increased to $32.98 \%$. The $p$ value per decade from radiographic analysis was 0.0005 .

Conclusion: This study suggests there is a high IR of an OP in cadavers (88.46\%). This may be a result of the average age of cadavers 78.1 and the technique used to locate the OP. Radiographic results were significantly lower and may be explained by an age factor. Radiographs reviewed were from an emergency room where the majority of patients receiving foot radiographs were between the ages of $19-45$. The clinical importance has been understated regarding the area of the os peroneum, which can be mistaken for styloid and Jones fractures.

Key words: Os peroneum, incidence, foot injury, foot fracture, fracture, sesamoid bone, Jones fracture, styloid process.

Accepted: January, 2011

Published: February, 2011

This is an Open Access article distributed under the terms of the Creative Commons Attribution License. It permits unrestricted use, distribution, and reproduction in any medium, provided the original work is properly cited. @The Foot and Ankle Online Journal (www.faoj.org)

$\mathrm{T}$ he purpose of this study was to examine the important clinical relevance of the 'os peroneum' (OP) within the fibularis longus (FLT) by investigating the incidence of the OP between cadaveric specimens and radiological images.

Address correspondence to: Oregon Health \& Science University 611 SW Campus Drive, Portland, OR 97239.

${ }^{1}$ Department of Surgery, Department of Integrative Biosciences, Department of Orthopaedic Surgery \& Rehabilitation, Department of Oral Maxillofacial Surgery, Oregon Health \& Science University, Portland, OR.

${ }^{2}$ Department of Integrative Biosciences, Oregon Health \& Science

University, Portland, OR.
The 'os peroneum' within the fibularis (peroneus) longus tendon has a history of controversy regarding its incidence in both individual and combined radiographic and cadaver studies. Radiographic and cadaveric studies have reported incidence rates of the OP within the FLT, however, a limited number of anatomical textbooks and atlases used by healthcare professionals and trainees mention or illustrate the OP. 




Figure 1 Os peroneum in the fibularis longus tendon. (Reproduced with kind permission from Lippincott Williams \& Wilkins, Grant's Anatomy, $12^{\text {th }}$ edition.)

Research to date reports a wide variation of incidence rates (IR), which are different in radiographic and cadaveric research. Previously Cilli, et al., in 2005 conducted a radiographic study on males only reporting 31.8\% IR. A cadaveric study was conducted by Muehleman, et al., in 2009 which reported a 46\% IR. Despite the various studies conducted thus far, no previous studies have conducted a comparison of incidence rates between radiographs and cadavers from separate populations. The objective of this research project was to assess radiograph incidence versus cadaver incidence rates of OP within the FLT and to assess why broad variants have occurred in previous radiograph and cadaver studies. (Fig. 1 and Fig. 2)

\section{Methods}

A literature search was conducted of anatomical texts and atlases, specialty texts, journals and websites regarding the presence or incidence of the $\mathrm{OP}$ within the FLT. Oblique foot radiographs from 1,025 individuals (range 10-89) were examined to identify OP within the FLT. (Fig. 3A and 3B) Dissection of 82 (156 sides) embalmed cadavers $(52 \mathrm{M}, 30 \mathrm{~F})$ with a mean of 78.1 years (range 45- 89) was performed to identify the incidence rate of the OP within the FLT. A skin incision was made from the fifth toe to the styloid process distal to proximal along the lateral border of the foot. Then an oblique incision was made to the lateral malleolus to expose the FLT. (Fig. $4 \mathrm{~A})$

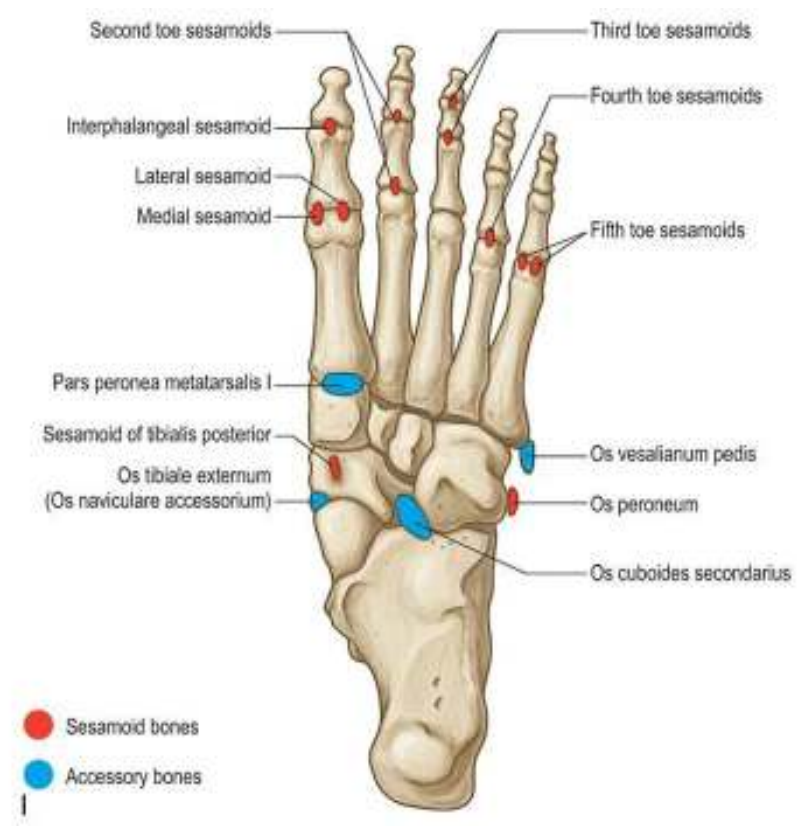

Figure 2 Location of os peroneum in the foot. (Reproduced with kind permission from Elsevier, Gray's Anatomy, $40^{\text {th }}$ edition.)

At the styloid process a horizontal incision was made along the surface of the foot to the opposite side, then exposing the FLT within the tunnel it traverses. The FLT was freed from its attachment point distally and reflected back. Palpation of the FLT was performed to identify the OP. A longitudinal incision was performed $2 \mathrm{~cm}$ proximal and distal to the OP and then opened to reveal the 'sesamoid bone's' existence or not. (Fig. 4B) A second examiner palpated and analyzed the longitudinal incision and reported their findings. A paired t-test was conducted on the radiographic data.

\section{Results}

The literature search revealed the OP within the FLT was discussed in anatomy texts $(7.69 \%)$, contemporary atlases $(20 \%)$ and specific imaging texts $(16.6 \%)$. This study's radiographic evaluation of OP within the FLT from 1,025 individuals with a mean age of 41.97 years had an incidence rate of $15.12 \%$ overall. 

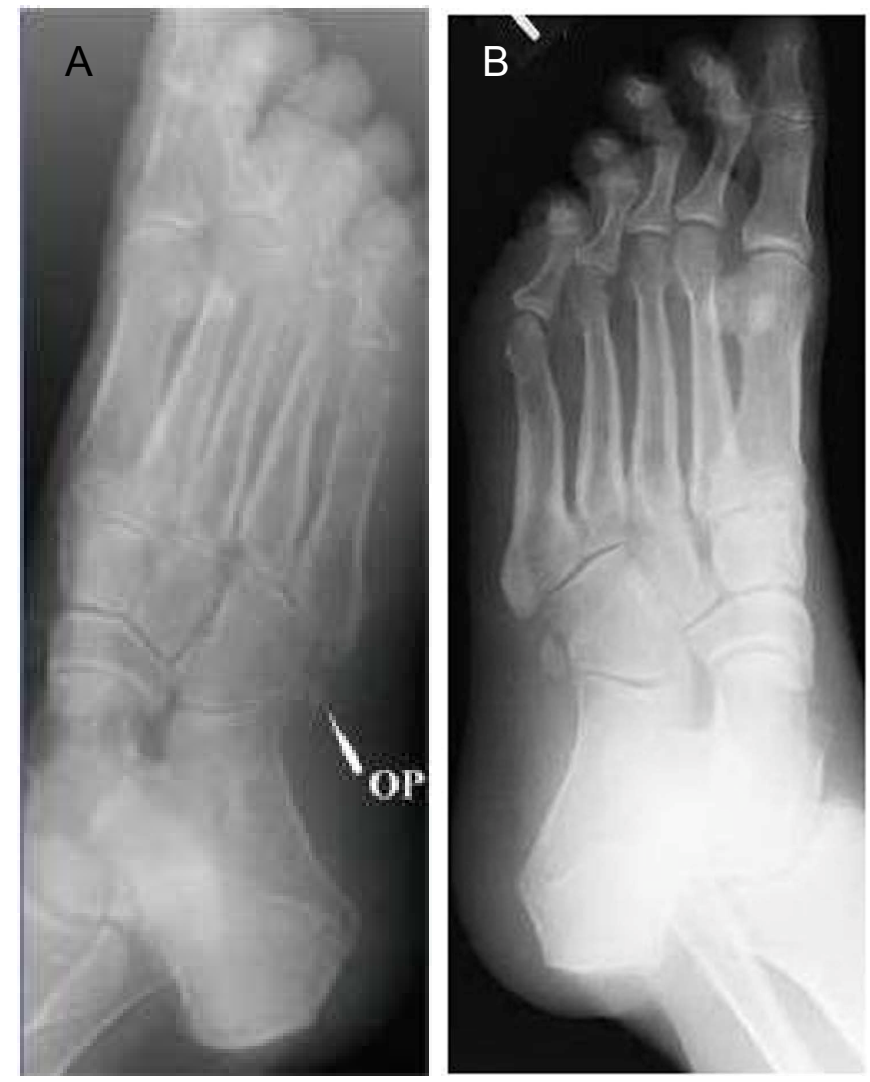

Figure 3A and 3B Oblique radiographs of the $\mathrm{OP}$ in the FLT. (A and B) (Thanks to the OHSU Radiology Department for radiograph.)

Incidence by ten-year increments revealed $12.16 \%$ for $10-19$ years, $11.31 \%$ for $20-29$ years, $13.87 \%$ for 30 39 years, $16.17 \%$ for $40-49$ years, $15.15 \%$ for $50-59$ years, $10 \%$ for $60-69$ years, $41.38 \%$ for $70-79$ years, and $19.44 \%$ for $80-89$ years. The number of radiographs analyzed per ten-year increment was from approximately 100 individuals. (Graphs 1 and 2) The $\mathrm{p}$ value for the radiographic images was 0.0005 . In this study, the incidence rate of the cadaver dissections was $88.46 \%$ with a mean age of 78.1 .

\section{Discussion}

The OP is a sesamoid bone that is located within the FLT. $^{12}$ The shape of the OP can be round, oval, triangular, irregular and can also be found as bipartite or multipartite.
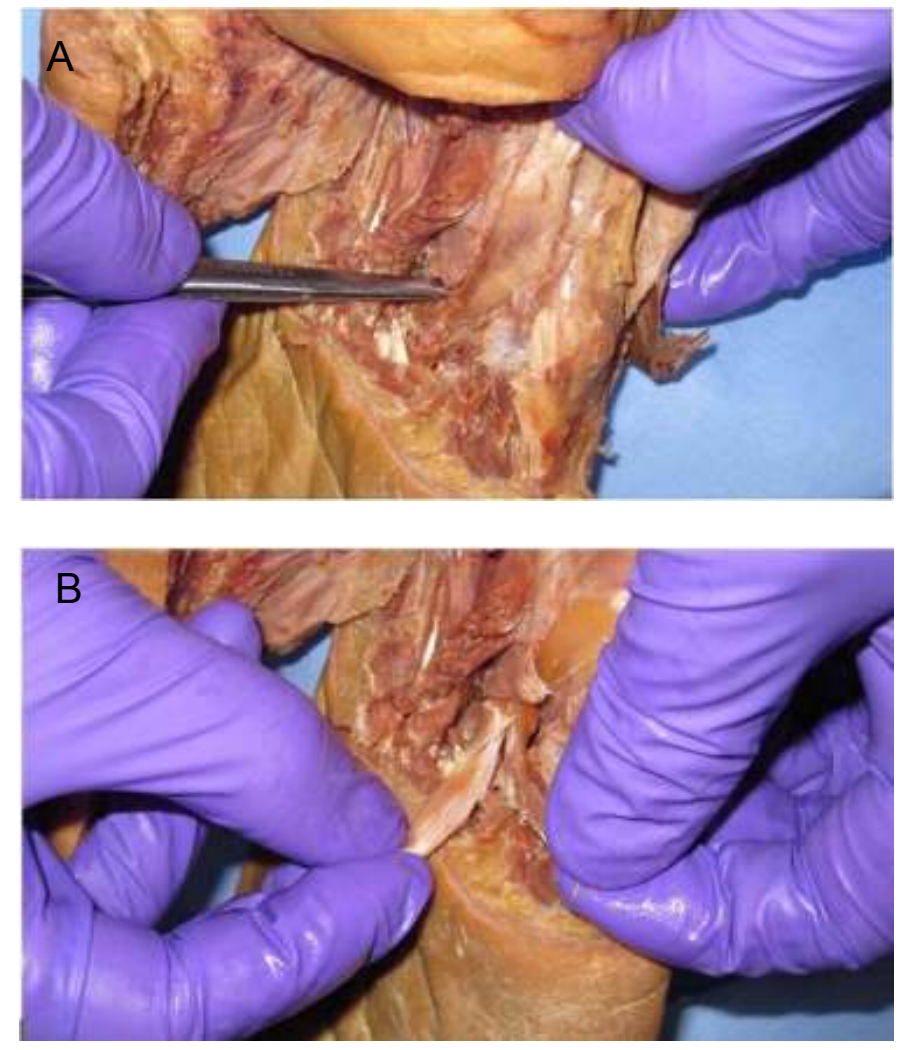

Figure 4A and 4B OP within the FLT in a cadaver.

The etiology of the OP is unknown; however, it has been thought that it arises from both mechanical and genetic factors. ${ }^{7,11}$ A literature search of contemporary anatomical texts, atlases and specialty radiographic texts revealed incidence rates of $7.69 \%$, $20 \%$ and $16.6 \%$, respectively. This lack of recognition of the OP in commonly used texts and atlases contradicts radiographic and cadaver evidence from our study.

Our study's incidence rate of identifying the OP within the FLT from radiographs $(15.12 \%)$ was consistent with other radiographic studies. (Table 1). Radiographic studies report incidence rates of $31.8 \%$, $4.7 \%, 14 \%, 14 \%$ and $9 \% .{ }^{3,4,111,13}$ The reason the incidence of the OP within the FLT in the images of our study was less than cadaveric results may be due to the average age of the individuals from the radiographs (41.97 years). 


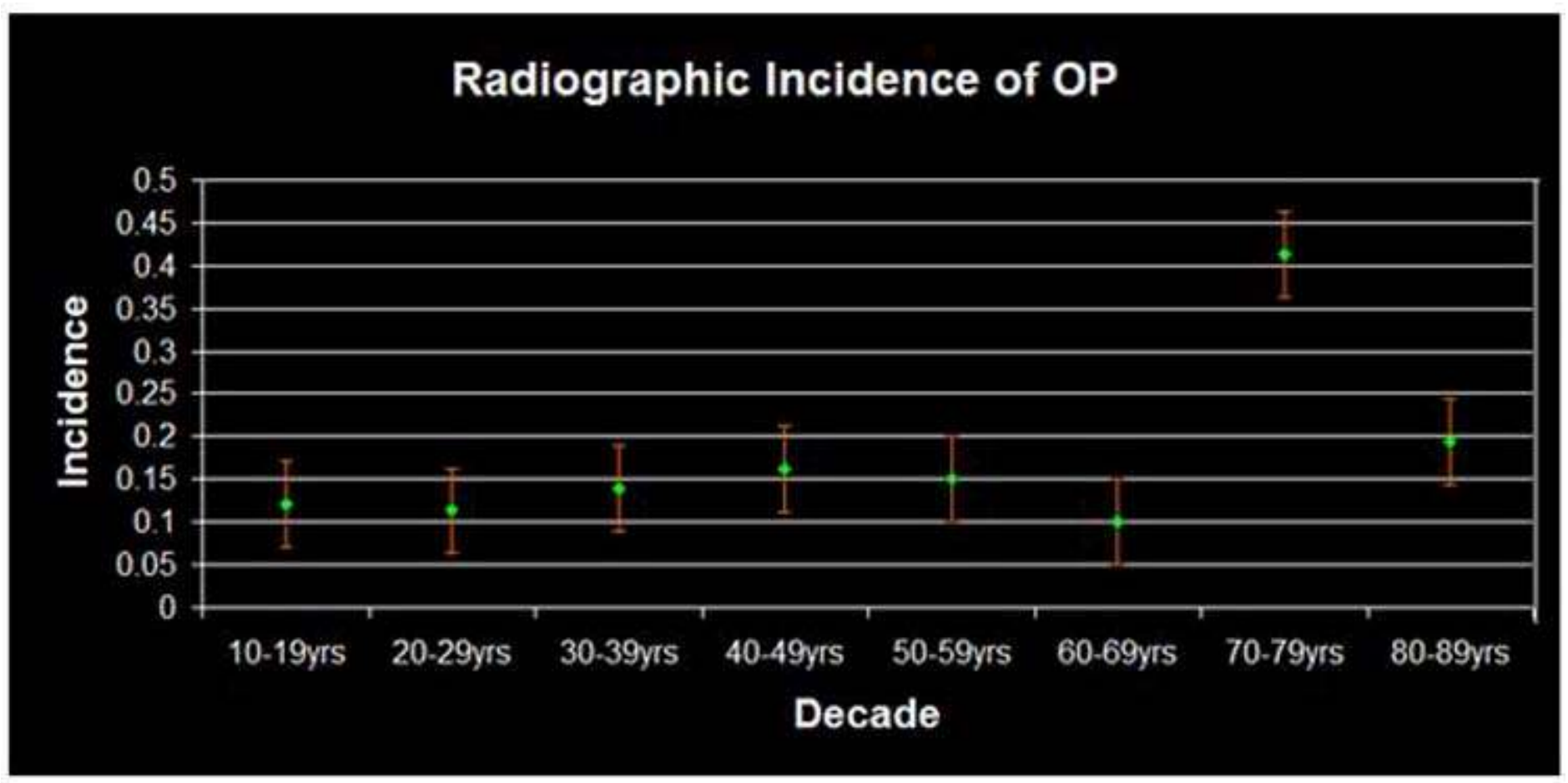

Graph 1 Radiographic incidence of the OP within the FLT per ten-year increment.

The radiographs reviewed were from an emergency room where on average the majority of patients receiving foot radiographs are between the ages of 1961. 'The incidence rate might have been higher if the average age of the individuals was higher. Another study had a mean age of 51 years. ${ }^{11}$ Two other studies only provided the range of their subjects and none were greater than 72 years. ${ }^{3,4}$ Two other radiographic studies did not provide any information on the mean age or range. ${ }^{1,13}$ To collect comprehensive research on the radiographic incidence of the OP within the FLT, further data is required in the age range of 60 and up.

The IR of the OP within the FLT in the cadavers $(88.46 \%)$ was consistent with one cadaveric study with an incidence rate of $90 \% .^{8}$ This consistency may be related to similar methods of identification of the OP within the FLT. Recent cadaveric studies have reported incidence rates of $46 \%$ and $14.9 \%{ }^{7,10}$
One study assessed radiographic imaging from the 33 cadavers dissected, but did not look at separate populations for radiographic and cadaveric data. ${ }^{7}$ Furthermore, that study did not report the incidence rate of the OP within the FLT when solely palpating the FLT on cadavers; their incidence rate was reported after radiographic and histologic investigation. A combined radiographic (500 individuals) and cadaveric (20 cadavers) study showed $12.3 \%$ incidence rate; this study did not separate incidence rates for radiographic and cadaveric results. ${ }^{5}$

In our study, the average age of the cadavers (78.1 years) is much older than the average age of the individuals in the radiographs, which may contribute to the high incidence rate of the OP within the FLT in the cadavers. Other studies that researched incidence rate of the OP within the FLT in cadavers had mean ages that were consistent with our study (81.0, 75.2 and 77.7 years). ${ }^{7,810}$ However, the age range (33-97 years) was only given for one of these studies. $^{8}$ 


\section{Literature Search of Contemporary Texts}

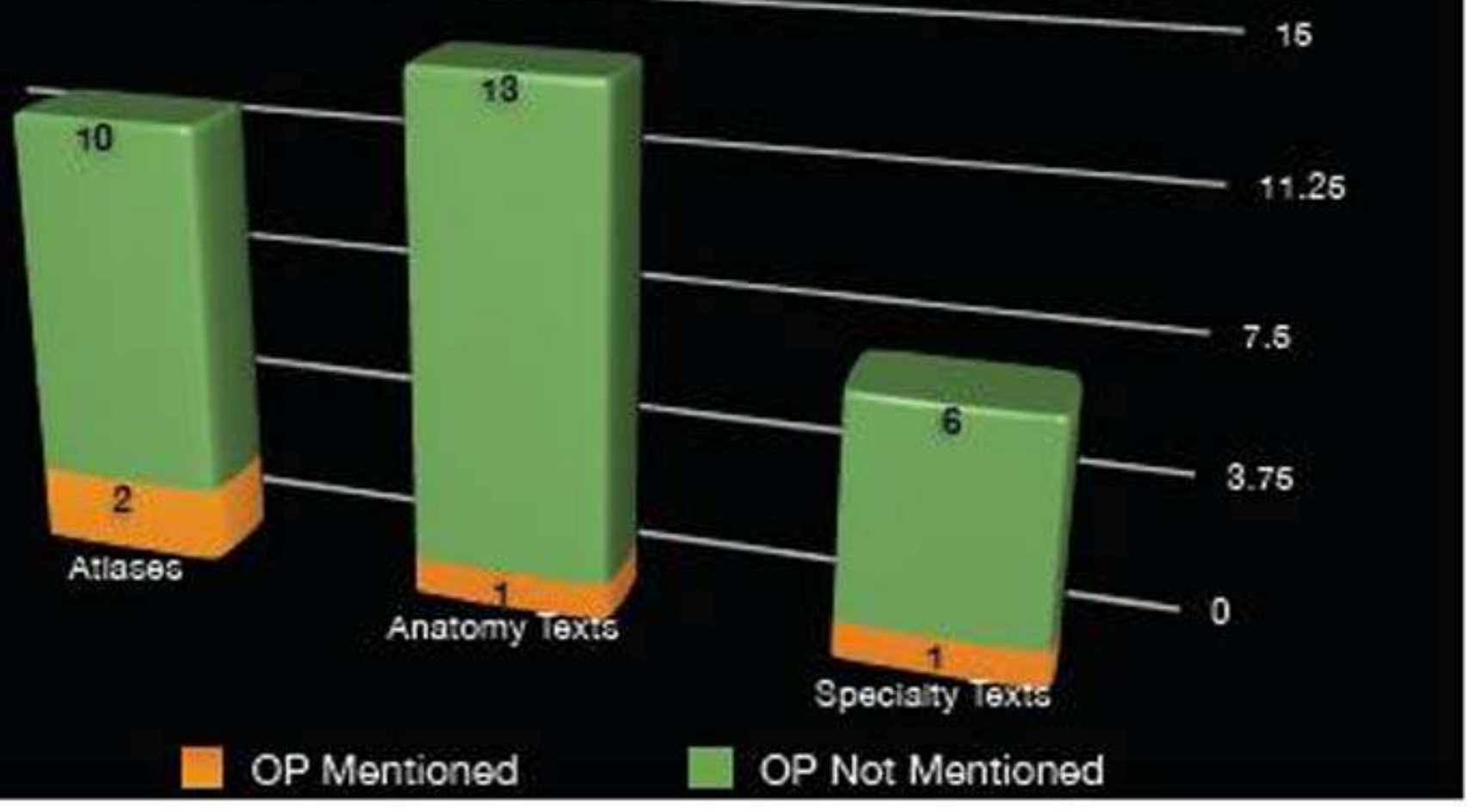

Graph 2 Identification of the OP within the FLT in educational texts.

The method of identification may also contribute to the high incidence rate of the OP within the FLT because our study palpated and dissected open the OP, but did not use histology or radiology to confirm presence of OP from cadavers.

A conflict between cadaveric and radiographic results is the fact that cadaver incidence can be based on a partially ossified OP. Therefore a partially ossified OP could be recorded as positive. In contrast, an incomplete ossification may not be obvious or present on typical radiographs. A partially ossified OP can be cartilaginous and at times cartilage cannot be recognized on ordinary (not over or under penetrated images) radiographic images. ${ }^{12}$
A possible factor affecting the radiographic results of our study is that we used only those patients who presented to the emergency room with foot pain. It is not common for people over age 60 to present to the emergency room with sprained ankles or fractured $5^{\text {th }}$ metatarsals. The over 60 age group population present acutely with hip fractures or with gout of the great toe. There may have been different results if we had randomly chosen from the general population for $\mathrm{OP}$ in the FLT. 


\begin{tabular}{|c|c|c|c|c|c|}
\hline 1able 1 & $\begin{array}{l}\text { Cadaveric } \\
\text { Incidence } \\
\text { Rate }\end{array}$ & $\begin{array}{l}\text { Radiographic } \\
\text { Incidence } \\
\text { Rate }\end{array}$ & $\begin{array}{l}\text { Number of } \\
\text { Cadavers/ } \\
\text { Radiographic } \\
\text { Images }\end{array}$ & $\begin{array}{l}\text { Mean Age and } \\
\text { Range of Subjects }\end{array}$ & Other \\
\hline $\begin{array}{l}\text { Benninger } \\
\text { and } \\
\text { Kloenne, } \\
2010\end{array}$ & $88.46 \%$ & $15.12 \%$ & $\begin{array}{l}82 \text { cadavers; } \\
1025 \text { images }\end{array}$ & $\begin{array}{c}\text { Cadavers } 78.1 \\
\text { years (45- } \\
89 y r) ; \text { subjects } \\
41.97 \text { years } \\
(10-89 y r)\end{array}$ & \\
\hline $\begin{array}{c}\text { Muehleman et } \\
\text { al., } 2009\end{array}$ & $46 \%$ & & 33 cadavers & 81 years & $\begin{array}{l}\text { Confirmed OP with } \\
\text { radiographic/histologic } \\
\text { evidence }\end{array}$ \\
\hline $\begin{array}{c}\text { Coskun et al., } \\
2009\end{array}$ & & $4.7 \%$ & 984 images & $\begin{array}{c}534 \text { subjects (14- } \\
72 \mathrm{yr}) ; 450 \\
\text { subjects (14-60yr) }\end{array}$ & \\
\hline $\begin{array}{c}\text { Oyedele et al., } \\
2006\end{array}$ & $90 \%$ & & 40 cadavers & 75 years $(33-97 y r)$ & \\
\hline Cilli et al., 2005 & & $31.8 \%$ & $\begin{array}{l}464 \text { images (all } \\
\text { male) }\end{array}$ & $(20-46 y r)$ & \\
\hline $\begin{array}{c}\text { Rühli et al., } \\
2003\end{array}$ & $14.9 \%$ & & 62 cadavers & 77.7 years & \\
\hline $\begin{array}{c}\text { Sarin et al., } \\
1999\end{array}$ & & $14 \%$ & 112 images & 51 years $(19-84 y r)$ & \\
\hline Le Minor, 1986 & $12.3 \%$ & $12.3 \%$ & $\begin{array}{c}500 \text { images; } 20 \\
\text { cadavers }\end{array}$ & $\begin{array}{c}\text { Cadavers }(70-89) ; \\
\text { subjects } 35 \text { years } \\
(20-60 \mathrm{yr})\end{array}$ & $\begin{array}{l}\text { Combined radiographic } \\
\text { and cadaveric } \\
\text { incidence rates }\end{array}$ \\
\hline $\begin{array}{c}\text { Tsuruta et al., } \\
1981\end{array}$ & & $9 \%$ & 3,460 images & Over 7 years & Only abstract available \\
\hline $\begin{array}{l}\text { Burman and } \\
\text { Lapidus, } 1930\end{array}$ & & $14 \%$ & $\begin{array}{l}596 \text { individuals } \\
\text { (1,000 images) }\end{array}$ & & \\
\hline
\end{tabular}

Table 1 Review of OP within the FLT in radiographic and cadaveric studies.

\section{Conclusion}

The clinical importance has been understated regarding the area of the os peroneum, which can be mistaken for styloid and Jones' fractures. The radiograph IR was always over $10 \%$ regardless the age group while the cadaveric incidence rate was $88.46 \%$. This suggests that teaching the OP in the FLT is clinically relevant because lower limb injuries are common.

\section{References}

1. Burman MS, Lapidus PW. The functional disturbance caused by the inconstant bone and sesamoids of the foot. Arch Surg 1931 22: 936.

2. Carter DR, Orr TE, Fyhrie DP, Schurman DJ. Influences of mechanical stress on prenatal and postnatal skeletal development. Clin Orthop Relat Res 1987 219: 237-250.

3. Cilli F, Akcaoglu M. The incidence of accessory bones of the foot and their clinical significance. Acta Orthop Traumatol Turc 2005 39: 243-246.

4. Coskun N, Yuksel M, Cevener M, Arican RY, Ozdemir H, Bircan O, Sindel T, Ilgi S, Sindel M. Incidence of accessory ossicles and sesamoid bones in the feet: a radiographic study of Turkish subjects. Surg Radiol Anat 2009 31: 19-24. 
5. Le Minor JM. Comparative anatomy and significance of the sesamoid bone of the peroneus longus muscle (os peroneum). J Anat 1987 151: 85-99.

6. Mellado JM, Ramos A, Salvadó E, Camins A, Danús M, Saurí A. Accessory ossicles and sesamoid bones of the ankle and foot: imaging findings, clinical significance and differential diagnosis. Eur Radiol 2003 13: L164-L177.

7. Muehleman C, Williams J, Bareither ML. A radiologic and histologic study of the os peroneum: prevalence, morphology, and relationship to degenerative joint disease of the foot and ankle in a cadaveric sample. Clin Anat 2009 22: 747-754. 8. Oydele O, Maseko C, Mkasi N, Mashanyana M. High incidence of the os peroneum in a cadaver sample in Johannesburg, South Africa: possible clinical implication? Clin Anat 2006 19: 605-610.

9. Reason for Visits to Emergency Room - National Hospital Ambulatory Medical Care Survey 1998-2006. U.S. Department of Health and Human Services; Centers for Disease Control and Prevention; National Center for Health Statistics.

10. Rühli FJ, Solomon LB, Henneberg M. High prevalence of tarsal coalitions and tarsal joint variants in recent cadavers sample and its possible significance. Clin Anat 2003 16: 411-415. 11. Sarin VK, Erickson GM, Giori NJ, Bergman AG, Carter DR. Coincident development of sesamoid bones and clues to their evolution. Anat Rec 1999 257: 174-180.

12. Stranding, S. Gray's Anatomy: The Anatomical Basis of Clinical Practice, 40 ${ }^{\text {th }}$ ed. Philadelphia: Elsevier 2005, pg 1420.

13. Tsuruta T, Shiokawa Y, Kato A, Matsumoto T, Yamazoe Y, Oike T, Sugiyama T, Saito M. Radiological study of the accessory skeletal elements in the foot and ankle (abstract). J Jap Orthop Assoc 1981 55: 357-370. 